2000s-12

\title{
Protection, Lobbying, and Market Structure
}

\author{
Arye Hillman, Ngo Van Long, \\ Antoine Soubeyrand
}

Série Scientifique

Scientific Series

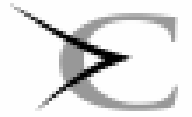

Ce I RAN N

en analyne des organisaticas

Montréal

Avril 2000 


\section{CIRANO}

Le CIRANO est un organisme sans but lucratif constitué en vertu de la Loi des compagnies du Québec. Le financement de son infrastructure et de ses activités de recherche provient des cotisations de ses organisationsmembres, d'une subvention d'infrastructure du ministère de la Recherche, de la Science et de la Technologie, de même que des subventions et mandats obtenus par ses équipes de recherche.

CIRANO is a private non-profit organization incorporated under the Québec Companies Act. Its infrastructure and research activities are funded through fees paid by member organizations, an infrastructure grant from the Ministère de la Recherche, de la Science et de la Technologie, and grants and research mandates obtained by its research teams.

\section{Les organisations-partenaires / The Partner Organizations}

•École des Hautes Études Commerciales

-École Polytechnique

-Université Concordia

-Université de Montréal

-Université du Québec à Montréal

-Université Laval

-Université McGill

-MEQ

-MRST

-Alcan Aluminium Ltée

-Banque Nationale du Canada

-Banque Royale du Canada

-Bell Québec

-Développement des ressources humaines Canada (DRHC)

-Fédération des caisses populaires Desjardins de Montréal et de l'Ouest-du-Québec

-Hydro-Québec

-Imasco

-Industrie Canada

-Raymond Chabot Grant Thornton

-Téléglobe Canada

-Ville de Montréal

(C) 2000 Arye Hillman, Ngo Van Long et Antoine Soubeyrand. Tous droits réservés. All rights reserved. Reproduction partielle permise avec citation du document source, incluant la notice $\odot$.

Short sections may be quoted without explicit permission, provided that full credit, including $\odot$ notice, is given to the source.

Ce document est publié dans l'intention de rendre accessibles les résultats préliminaires de la recherche effectuée au CIRANO, afin de susciter des échanges et des suggestions. Les idées et les opinions émises sont sous l'unique responsabilité des auteurs, et ne représentent pas nécessairement les positions du CIRANO ou de ses partenaires.

This paper presents preliminary research carried out at CIRANO and aims at encouraging discussion and comment. The observations and viewpoints expressed are the sole responsibility of the authors. They do not necessarily represent positions of CIRANO or its partners. 


\title{
Protection, Lobbying, and Market Structure*
}

\author{
Arye Hillman ${ }^{\dagger}$, Ngo Van Long ${ }^{\ddagger}$, Antoine Soubeyrand ${ }^{\S}$
}

\section{Résumé / Abstract}

On analyse un modèle de lobbying par des entrepreneurs qui allouent leur temps entre les activités de supervision. On donne des réponses aux questions suivantes : (i) quelles sont les allocations de ressources en équilibre? Le lobbying pourrait-il renverser l'ordre de rentabilité parmi les firmes? (iii) y a-t-il une corrélation entre le degré de concentration d'une industrie et la protection qu'elle obtient du gouvernement?

We analyze a model of lobbying by oligopolists who allocate resources between lobbying and internal cost-reducing activities. We ask the following questions: (i) if firms differ with respect to comparative advantage in lobbying, what is the equilibrium allocation of resources between lobbying and costreducing activities? (ii) can the possibility of lobbying reverse the profitability ranking among firms? (iii) under what condition is the conventional wisdom (that highly concentrated industries tend to obtain more protection) valid?

Mots Clés : Lobbying, oligopole, protection, quota

Keywords: Lobbying, oligopoly, protection, quota

JEL: F12, F13

\footnotetext{
* Corresponding Author: Ngo Van Long, CIRANO, 2020 University Street, 25 $5^{\text {th }}$ floor, Montréal, Qc, Canada H3A 2A5 Tel.: (514) 985-4020 Fax: (514) 985-4039 email: longn@cirano.umontreal.ca We would like to thank Professor Robert Staiger and an anonymous referee for very helpful comments and suggestions.

$\dagger$ Bar-Ilan University

$¥$ McGill University and CIRANO

$\S$ GREQAM, Université de Méditerranée
} 


\section{Introduction}

There is a presumption Ddating at least to Mancur Olson's (1965) classic analysis of collective action $\Gamma$ that small group size is advantageous in influencing endogenous policy. The argument is that $\Gamma$ under institutions of representative democracy Tgovernments and candidates for political office have politicalsupport needs than can be better satisfied by "cohesive" coalitions $\Gamma$ as these are less prone to defection and free-riding than more "diffuse" coalitions . Hence $\Gamma$ under representative democracy $\Gamma$ "the small exploits the large". In contrast $\Gamma$ under direct democracy where voters determine outcomes $\Gamma$ larger group size is more advantageous ${ }^{1}$. An implication of the advantage of small group size for collective action is that more concentrated industries should (all else equal) be more successful in securing protection and or in resisting trade liberalization. Empirical studies have however failed to find an unambiguous relation between industry concentration and policy effectiveness of an industry (see sthe surveys by Baldwin 1984 Hillman 1989ГPotters and Sloof 1996 and also Goldberg and Maggi 1999). Potters and Sloof (1996Г pp.417-418) summarize the diversity of the extensive empirical evidence as follows:

"Most scholars indeed find an increased scope for political influence with higher degrees of concentration but there are many that find no effect or even a negative effect. Equally ambiguous are the results of the use of numbers for the free rider effect. A large number of participants to collective action is usually hypothesized to increase the free riding problem. Sometimes indeed a negative effect of numbers on influence is reported. More often $\Gamma$ however $\Gamma \mathrm{a}$ positive effect is found. Hence there appears to be relatively little direct empirical support for the Olson (1965) influential theoretical study on collective action."

One may therefore well wonder what is going on. In this paper we consider theoretical foundations for the source of the empirical ambiguities. There are different possible points of departure. One beginning is George Stigler's (1964) proposal that a theory of oligopoly should start by assuming collectively rational behavior and then should proceed to investigate the costs of defection from the cooperative equilibrium. Stigler's perspective on oligopoly provides a reasonable basis for Olson's collective-action proposition. Smaller group size increases the probability of detection of free-riding behavior and

\footnotetext{
${ }^{1}$ For an overview of theories of collective action, see Sandler (1992).
} 
decreases the general transactions costs of organizing and monitoring contributions to collective action $\Gamma$ and so $\Gamma$ according to Stigler $\Gamma$ more concentrated industries are expected to be more effective in influencing endogenous policy decisions. This is not however the unambivalent picture provided by the empirical evidence. The alternative non-cooperative Cournot-Nash approach adopts as a point of departure individually rational behavior. Policy influence then becomes a case of non-cooperative private provision of a public good.

In the latter approach $\Gamma$ we have well-established results for the case where consumers choose public good provision (see Cornes and Sandler 1996). If the public good is a normal good $\Gamma$ there are countervailing substitution and income effects on the contribution decisions of other consumers when one consumer increases his or her Nash contribution $\Gamma$ so that a larger contribution by one consumer need not decrease the contribution of other consumers. Increasing group size and thereby adding a new prospective contributor to the public good therefore can either increase or decrease total contributions. Also The total Nash-equilibrium contribution by consumers to provision of a public good is independent of the distribution of income among those consumers who are making positive contributions to provision of the good (Warr 1983ГKemp 1984ГBergstromГBloom and Varian 1986).

The analogy to firms in an industry making contributions in pursuit of a collective policy objective is investigated in Hillman (1991). Consumers are replaced by owners of firms who allocate time and attention between the privately beneficial activity of monitoring their firms' production activities $^{2}$ and the public-good benefit of persuading policy makers to implement policies that benefit the entire industry. Firm owners have different comparative advantages in lobbying for protection ${ }^{3}$. Results are obtained that are analogous to the consumer outcome: redistribution of aggregate industry profits among a given number of firms in the industry in the size distribution of firms or industry concentration $\Gamma$ need not change the aggregate Nash contribution of resources by firms in the industry to the collective benefit of influencing policy. Prospective neutralities are therefore introduced into the relation between industry concentration and the effec-

\footnotetext{
${ }^{2}$ For an elegant treatment of the monitoring role of managers, see Vousden and Campbell (1994).

${ }^{3} \mathrm{Or}$, rather than firm ownership, management incentive schemes can provide the same incentive to lobby for industry protection even when this is not in the best interests of diversified owners of firm. See Cassing (1996).
} 
tiveness of the collective pursuit of policies beneficial to the industry; that is $\Gamma$ changes in concentration as measured by the distribution of profits among a given number of firms can leave unaffected the political influence of the industry as measured by the total resources allocated by the industry to policy persuasion. Changing group size by increasing the number of firms $\Gamma$ the neutralities appear when managerial time and attention available for allocation between productive activity and seeking political influence is an industry-specific input $\Gamma$ but not when such inputs are intersectorally mobile.

The model in Hillman (1991) assumes that the domestic industry wherein firms are contributing to collective policy objective confronts a competitive world market. International prices of import-competing output are thus exogenously determined $\Gamma$ and the domestic price is determined by the given world price plus the protection provided as a consequence of firms' contributions to lobbying efforts. The strategic interdependence amongst firms is thus only with respect to contributions to influencing policyГand not with respect to competition in the product market. This permits the industry seeking protection (or resisting liberalization) to be placed within the broader context of a competitive small-country model of international trade.

In this paper we consider the relation between industry concentration and policy effectiveness in an internationally oligopolistic industry rather than an internationally competitive industry. As in Hillman (1991) $\Gamma$ the firms seeking protection are heterogeneous (see also Long and Soubeyran 1996) $\Gamma$ and trade policy is endogenously responsive to the total resources contributed by domestic firms to influencing policy. In our model $\Gamma$ we show that the amount of resources that an oligopolist deploys for lobbying has an impact on the internal cost structure of the oligopoly each firm faces a resource constraint $\Gamma$ or each firm faces an upward-sloping curve of the marginal cost of funds that are to be allocated between political activities and internal cost-reducing activities. Because of these factors $\Gamma$ as well as the oligopolistic market structure and the consequent endogeneity of domestic price $\Gamma$ contributions by firms to influencing policy no longer have the characteristics of contributions to a pure public good. We show how in these circumstances the industry equilibrium is influenced by the properties of the lobbying technology and the domestic demand function $\Gamma$ and we establish how an index of concentration is related to effectiveness of collective action of the industry. The specific questions which we address are: (i) With firms differing in comparative advantage in lobbying what are the characteristics of the equilibrium allocations by firms between privately profitable monitoring 
and collectively beneficial lobbying activities? (ii) Can the ranking of firms' profitability be reversed by the introduction of lobbying possibilities? And most basically: (iii) What can be said about the conventional wisdom that more concentrated industries should obtain more protection?

The model which provides the framework for these questions is set out in Section 2. We consider the outcomes when lobbying by firms is noncooperative and cooperative in Sections 3 and 4 respectively. The final section summarizes the conclusions.

Before proceeding with the model $\Gamma$ we note that our endogenous-policy specification is general in not presupposing any one particular mechanism which translates lobbying inputs into endogenous policy outcomes ${ }^{4}$. We simply assume that an increase in the resources available to the industry to influence policy enhances the lobbying effectiveness of the industry. The model is in principle consistent with an underlying political-support function of an incumbent government (for example Hillman 1982) or influence over candidates' trade policy platforms in the context of political competition (Hillman and Ursprung 1988ГMayer 1998). In neither type of specification in the literature do we find an investigation of the collective-action incentives associated with industry concentration with which we are concerned ${ }^{5}$. For example in the micro-foundations for political support proposed by Grossman and Helpman (1994) Гeither an industry has been successful in perfectly internalizing collective action problems to permit collectively optimal political behavior $\Gamma$ or otherwise the industry is not at all politically active ${ }^{6}$. Hence $\Gamma$ in Grossman-Helpman $\Gamma$ the issue of the market structure of the industryГand the consequences for collective action in responding to the policy maker's readiness to "sell protection" $\Gamma$ do not at all arise. In models where trade policy is endogenously determined as the equilibrium outcome of political competition (as in Hillman-Ursprung 1988) Tmarket structure implicitly affects the competing candidates' policy platforms $\Gamma$ but in a rather simple way because of the homogeneity of firms; the political competition models can in principle address the issue of the relation between concentration and

\footnotetext{
${ }^{4}$ See Potters, Sloof, and van Winden (1997) for a model which encompasses different channels of influence on voters decisions.

${ }^{5}$ The issue is also not addressed in the surveys by Magee (1984) and Rodrik (1995).

${ }^{6}$ Grossman and Helpman indeed require the assumption that some industries are not politically active to avoid a free-trade policy equilibrium, since their choice of equilibrium implies a Pareto-efficient outcome if all industries are politically active. See also Mitra (1995).
} 
effectiveness of policy influence but only in the sense of measurement of industry concentration in terms of the number of identical firms composing the industry ${ }^{7}$.

\section{The Model}

There are $n$ firms producing a homogenous good. The first $k$ firms are domestic firms and the remaining $n-k=k^{*}$ firms are foreign firms. Let $K=\{1,2, \ldots, k\}$ and $K^{*}=\left\{k+1, \ldots k+k^{*}\right\}$. Their outputs are denoted by $q_{i} \Gamma i \in K$ Tand $q_{j}^{*} \Gamma j \in K^{*}$. Let

$$
Q=\sum_{i \in K} q_{i} \quad, \quad Q^{*}=\sum_{j \in K^{*}} q_{j} \quad, \quad Z=Q+Q^{*}
$$

All the outputs are sold in the home country $\Gamma$ where the inverse demand function is $P=P(Z) \Gamma P^{\prime}<0$.

The unit variable cost of firm $i$ is $c_{i}$. It is independent of the output level $\Gamma$ but is dependent on the amount of resources (which may be entrepreneurial time or funds) devoted to internal cost-reducing activities (such as monitoring or R\&D) $\Gamma$ which we denote by $m_{i}$. We assume that $c_{i}(0)=\bar{c}>0$ and $c_{i}^{\prime}\left(m_{i}\right) \leq 0$. Each domestic firm has a total amount $h_{i}$ of resources to be allocated between cost-reducing activities and lobbying. Let $a_{i}$ denote the amount of resources devoted to lobbying $\Gamma$ then $a_{i}=h_{i}-m_{i}$. Concerning the quantity $h_{i}$ Гwe consider two cases: in case (i) $\Gamma$ the amount $h_{i}$ is fixed (exogenously given) $\Gamma$ and in case (ii) $\Gamma$ the amount $h_{i}$ can be chosen $\Gamma$ but the firm must incur a cost $\Omega\left(h_{i}\right) \geq 0$ to obtain $h_{i}$, and $\Omega^{\prime} \Gamma$ the marginal cost of obtaining $h_{i}$ Tis an increasing function of $h_{i}$. A possible interpretation of case (i) is that firms have a certain fixed amount of money (or time) to spend on the two classes of activities mentioned above $\Gamma$ and if they spend more on lobbying $\Gamma$ then less will be spent on internal activities. A possible interpretation of case (ii) is that $h_{i}$ represents the amount of money that can be obtained from financial institutions $\Gamma$ but the marginal cost of loans $\Gamma$ denoted

\footnotetext{
${ }^{7}$ The political competition models of endogenous trade-policy determination are similar to models of rent seeking for public goods (see the survey of the rent-seeking literature by Nitzan 1994). Although the model structures are similar (see Urpsrung 1990), the rent-seeking models focus on establishing the social loss incurred via resource dissipation in different circumstances, whereas the political-competition models of trade focus on establishing the characteristics endogenous equilibrium policies.
} 
by $\Omega_{i}^{\prime}\left(h_{i}\right) \Gamma$ is increasing. Alternatively $\Gamma$ if $h_{i}$ is the amount of time devoted to monitoring and lobbying $\Gamma$ then $\Omega\left(h_{i}\right)$ is the entrepreneur's evaluation of lost leisure. In both case (i) and case (ii) if the resources are money rather than entrepreneurial time $\Gamma$ then some sort of capital market imperfection must be in the background. In the finance literature $\Gamma$ it has been argued that credit rationing is a response to asymmetric information $\Gamma$ and rising marginal cost of loans is a reflection of firm-specific risks $\Gamma$ which make the I.O.U. s issued by the firm a specific asset without perfect substitutes.(See $\Gamma$ for example $\Gamma M i l n e$ 1975ГHellwig 1989 Гand Bester and Hellwig 1987.) In what follows Twe focus on case (i) $\Gamma$ because the analysis of that case is relatively simpler. Results for case (ii) are similar to those obtained in case (i) $\Gamma$ and they are reported in the Appendix.

While a great deal of lobbying activities are undertaken by hired professional lobbyists $\Gamma$ the importance of entrepreneurial time in lobbying (and $\Gamma$ more generally $\Gamma$ in public relation activities) is also well recognized in the business world. The frequent public appearances of well-known individuals such as Lee Ioccoca and Bill Gates are not without opportunity costs in terms of internal controls. In Canada $\Gamma$ when chief executive officers are chosen $\Gamma$ an important criterion is their connection with Ottawa ${ }^{8}$.

We assume that firms lobby in order to convince the government to impose a quota $B$ on the aggregate import of the good. We postulate that $B$ is a decreasing function of aggregate lobbying effort $\Gamma A=\sum_{i \in K} a_{i}$ and that there is diminishing returns to lobbying:

$$
B^{\prime}(A)<0, \quad B^{\prime \prime}(A)>0
$$

In what follows $\Gamma$ for simplicity $\Gamma$ the quota is taken to be binding always $\Gamma$ so that $Q^{*}=B \Gamma$ and $Z=B+Q$. It does not matter $\Gamma$ therefore $\Gamma$ if foreign firms are oligopolists or not. Domestic firms solve their optimization problem in two stages. In Stage $1 \Gamma$ the $a_{i}$ 's are chosen $\Gamma$ either cooperatively or noncooperatively $\Gamma$ and this determines the quota $B \Gamma$ and the amount $m_{i}=h_{i}-$ $a_{i} \geq 0$ is spent on internal cost-reducing activities (monitoring $\Gamma$ or $\mathrm{R} \& \mathrm{D}$ ). In Stage $2 \Gamma$ given $B \Gamma$ domestic firms choose non-cooperatively their output levels. The game in Stage 2 is a simple Cournot game 5 the solution of which is described below.

Given $m_{i} \Gamma$ firm $i$ 's unit cost is $c_{i}\left(m_{i}\right) \Gamma$ which we denote by $c_{i}$ for short. Firm $i$ takes as given the import volume $B$ and the total output of all other

\footnotetext{
${ }^{8}$ See, for example, the Globe and Mail (11 March, 1999).
} 
domestic firms $\Gamma$ denoted by $Q_{-i}$. It chooses $q_{i}$ to maximize profit

$$
\pi_{i}=P\left(B+Q_{-i}+q_{i}\right) q_{i}-c_{i} q_{i}
$$

This yields the first order condition for an interior maximum

$$
q_{i} P^{\prime}\left(B+Q_{-i}+q_{i}\right)+P\left(B+Q_{-i}+q_{i}\right)=c_{i}
$$

The second order condition is

$$
s_{i d} E_{d}<2
$$

where $s_{i d} \equiv q_{i} / Q$ is domestic firm $i$ 's market share of domestic output $\Gamma$ and $E_{d} \equiv\left(Q P^{\prime \prime}\right) /\left[-P^{\prime}\right]$ is the elasticity of the slope of the residual (ieГnet of imports) demand curve. Summing the first order condition over all domestic firms yields

$$
Q P^{\prime}(B+Q)+k P(B+Q)=C \equiv \sum_{i \in K} c_{i}
$$

Equation (??) shows that given the quota $B \Gamma$ domestic output $Q$ is a function of the sum of unit $\operatorname{costs} \Gamma C$. Let us denote the left-hand side of (??) by $\psi(Q, B)$. We assume that $\psi_{Q}<0$. This condition may be expressed as

$$
E_{d}<k+1
$$

Condition (??) is one of the usual stability conditions of a Cournot equilibrium $\Gamma$ see Dixit (1986). Given this assumption $\Gamma$ we can use equation (??) to obtain the equilibrium domestic output as a function of $B$ and $C \Gamma$ $Q=Q(B, C)$,with

$$
\frac{\partial Q}{\partial B}=\frac{k-E_{d}}{E_{d}-k-1} \quad, \quad \frac{\partial Q}{\partial C}=\frac{1}{\left[-P^{\prime}\right]\left[E_{d}-k-1\right]}<0
$$

It follows that total demand $\Gamma=B+Q \Gamma$ is a function of $B$ and $C \Gamma$ $Z=Z(B, C)$,with

$$
\frac{\partial Z}{\partial B}=\frac{-1}{E_{d}-k-1}>0, \quad \frac{\partial Z}{\partial C}=\frac{1}{\left[-P^{\prime}\right]\left[E_{d}-k-1\right]}<0
$$

Equation (??) shows that lobbying has two effects on equilibrium supply and hence price. An increase in lobbying will reduce the quota $B$ Thus raising the equilibrium domestic price. In addition $\Gamma$ an increase in lobbying means 
that $\Gamma$ for a given $h_{i}$ Cless resources will be available for monitoring (or R\&D) $\Gamma$ hence cost will rise and this reduces equilibrium domestic output Tcausing a further upward pressure on price. (In case (ii) $\Gamma$ which we analyse briefly in the Appendix $\Gamma h_{i}$ can be increased $\Gamma$ but then a higher marginal cost of funds $\Gamma$ $\Omega^{\prime}\left(h_{i}\right) \Gamma$ will be incurred; thus in this case an increase in lobbying will also has an impact on the cost of internal activities.) Note that while $B$ depends only on the sum of the $a_{i}$ 's $\Gamma$ the variable $C$ depends on the whole vector $a=\left(a_{1}, \ldots, a_{k}\right)$ and not on the sum of the $a_{i}$ 's. This observation is crucial $\Gamma$ because it means that the model of Bergstrom $\Gamma$ Blume and Varian (1986) $\Gamma$ which postulates that only the sum of the contributions matters $\Gamma$ does not apply to our more complex situation.

Let us turn to the equilibrium output of firm $i$. From (??) we have

$$
q_{i}=\frac{P[B+Q(B, C)]-c_{i}}{\left\{-P^{\prime}[B+Q(B, C)]\right\}}
$$

and its equilibrium profit is

$$
\pi_{i}=\left\{P-c_{i}\right\} q_{i}=\frac{\left\{P[B+Q(B, C)]-c_{i}\right\}^{2}}{\left\{-P^{\prime}[B+Q(B, C)]\right\}}
$$

In what follows $\Gamma$ we assume that if $c_{i}$ falls while all the $c_{j}$ 's $(j \neq i)$ remain constant $\Gamma$ then the equilibrium profit will rise. It can be shown that this assumption is satisfied if

$$
\left(2-s_{i d}\right) E_{d} \leq 2 k
$$

(i.e. if the demand curve is not too convex.)

We now turn to the analysis of the equilibrium in stage $1 \Gamma$ the lobbying stage.

\section{Non-cooperative Lobbying}

In this section we assume that firms undertake lobbying activities in a noncooperative way. This is an instance of a class of problems known as "the private provision of a public good." A special case of this class of problems has been analyzed thoroughly by Bergstrom $\Gamma$ Blume $\Gamma$ and Varian (1986) $\Gamma$ where they assume that (i) in the production of the public good only the sum of the contributions $\Gamma A \equiv \sum a_{i}$ Tmatters $\Gamma$ and that (ii) the payoff to each player depends only on this sum $\Gamma A$ Tand on his own contribution 
how much each of the other players contributes. As we have stated above $\Gamma$ their restrictive assumptions mean that their model is not applicable to our problem $\Gamma$ where each firm $i$ 's payoff depends not only on $A$ but also on $C \Gamma$ and the latter is not a function of the sum $A$. Clearly iit is important how $C$ depends on the individual contributions $a_{i}$ 's. In what follows $\Gamma$ we will focus on three alternative specifications of the relationship between $C$ and the $a_{i}$ 's. Let us write

$$
c_{i}\left(m_{i}\right)=\bar{c}-r_{i}\left(m_{i}\right)
$$

where $r_{i}\left(m_{i}\right)$ may be interpreted as the reduction in unit cost due to monitoring.

Specification 1: increasing returns to monitoring.

$$
r_{i}\left(m_{i}\right)=\delta_{i} m_{i}^{\alpha} \quad, \quad \alpha>1, \quad \delta_{i}>0, \quad 0 \leq m_{i} \leq h_{i}
$$

Specification 2: decreasing returns to monitoring.

$$
r_{i}\left(m_{i}\right)=\delta_{i} m_{i}^{\epsilon} \quad, 0<\epsilon<1, \quad \delta_{i}>0, \quad 0 \leq m_{i} \leq h_{i}
$$

Specification 3: constant returns to monitoring.

$$
r_{i}\left(m_{i}\right)=\delta_{i} m_{i} \quad, \quad \delta_{i}>0, \quad 0 \leq m_{i} \leq h_{i}
$$

Since $m_{i}=h_{i}-a_{i}$ Tit is convenient to define

$$
\theta_{i}\left(a_{i}\right)=\bar{c}-r_{i}\left(h_{i}-a_{i}\right)
$$

and $\theta_{i}^{\prime}\left(a_{i}\right)$ may be interpreted as the marginal cost of lobbying $\Gamma$ because it measures the increase in production cost when entrepreneurial resources are diverted away from internal cost-reducing activities. Let $a=\left(a_{1}, \ldots, a_{k}\right)$. Then $\Gamma$ with a slight abuse of notation $\Gamma Z(B, C)=Z(a)$. From (??) $\Gamma$ firm $i$ 's profit in stage 2 is

$$
\pi_{i}=\frac{\left[P(Z(a))-\theta_{i}\left(a_{i}\right)\right]^{2}}{\left[-P^{\prime}(Z(a))\right]}
$$

To find firm $i$ 's optimal choice of $a_{i}$ Tgiven the $a_{j}$ 's $(j \neq i)$ Гwe maximize (??) subject to the constraints $h_{i}-a_{i} \geq 0$ and $a_{i} \geq 0$. Write the Lagrangian

$$
L=\pi_{i}+\lambda_{i}\left[h_{i}-a_{i}\right]+\mu_{i} a_{i}
$$


The first order condition is

$$
\frac{\partial L}{\partial a_{i}}=M\left(a_{i}\right) N\left(a_{i}\right)-\lambda_{i}+\mu_{i}=0
$$

where

$$
M\left(a_{i}\right) \equiv \frac{P-\theta_{i}\left(a_{i}\right)}{\left[-P^{\prime}\right]\left(k+1-E_{d}\right)}>0
$$

and

$$
N\left(a_{i}\right) \equiv-\left[2 k-E_{d}\left(2-s_{i d}\right)\right] \theta_{i}^{\prime}+\left[2-s_{i d} E_{d}\right] B^{\prime} P^{\prime}
$$

At an interior maximum we must have

$$
\theta_{i}^{\prime}\left(a_{i}\right)=\frac{\left[2-s_{i d} E_{d}\right] B^{\prime} P^{\prime}}{\left[2 k-E_{d}\left(2-s_{i d}\right)\right]}
$$

(note that both $2-s_{i d} E_{d}$ and $2 k-E_{d}\left(2-s_{i d}\right)$ are positive Condition (??) has an intuitive interpretation: at an interior maximum $\Gamma$ an increase in the amount of resources devoted to lobbying will increase production cost by $\theta_{i}^{\prime} \Gamma$ (this is the marginal cost of lobbying) and this must be balanced by the marginal gain from lobbying $\Gamma$ which consists of an increase in price (modified for factors such as market share $\Gamma$ and the effect of a price rise on revenue) brought about by a decrease in the import quota. The maximum may occur at a corner: zero contribution to lobbying $\Gamma$ if $\theta_{i}^{\prime}(0)$ exceeds the marginal gain (the right-hand side of (??)); or maximum contribution $\Gamma$ $a_{i}=h_{i} \Gamma$ if $\theta_{i}^{\prime}\left(h_{i}\right)$ is smaller than the marginal gain.

The second order condition for an interior maximum is $M^{\prime}\left(a_{i}\right) N\left(a_{i}\right)+$ $M\left(a_{i}\right) N^{\prime}\left(a_{i}\right)<0$ ए which amounts to $N^{\prime}\left(a_{i}\right)<0$ because $N\left(a_{i}\right)=0$ at an interior maximum. If the demand function is linear $\Gamma P=a-b Z \Gamma$ the second order condition simplifies to

$$
-k \theta_{i}^{\prime \prime}\left(a_{i}\right)-b B^{\prime \prime}(A)<0
$$

which is satisfied if $\theta^{\prime \prime}$ is positive or not too negative.

The first order condition (??) can also be written as

$$
s_{i} E=2-2 \gamma_{i}[k+1-s E]
$$

where $s_{i} \equiv q_{i} / Z \Gamma s \equiv Q / Z \Gamma E \equiv\left[Z P^{\prime \prime}\right] /\left[-P^{\prime}\right]$, and $\gamma_{i}$ is defined by

$$
\gamma_{i} \equiv \frac{\theta_{i}^{\prime}\left(\hat{a}_{i}\right)}{\theta_{i}^{\prime}\left(\hat{a}_{i}\right)+P^{\prime} B^{\prime}(\hat{A})}
$$


where all the derivatives are evaluated at the Nash equilibrium over a variable indicates its equilibrium value. Equation (??) relates firm $i$ 's equilibrium market share to $\gamma_{i} \Gamma$ which may be taken as a measure of its comparative advantage in internal cost-reducing activities (which from now on we will refer to as monitoring for brevity.)

We now seek to determine how the heterogeneity among firms with respect to lobbying skills affect their relative contributions. Here several concepts of comparative and absolute advantage present themselves. We list below a few indicators.

(i) An indicator of absolute advantage in monitoring: If $\delta_{i}>\delta_{j}$ then firm $i$ is said to have absolute advantage in monitoring over firm $j$.

(ii) An indicator of comparative advantage in monitoring: Firm $i$ is said to have comparative advantage in monitoring over firm $j$ if and only if $\gamma_{i}>\gamma_{j}$ एwhere $\gamma_{i}$ is defined by (??). This definition is motivated by the idea that a firm that has comparative advantage in monitoring would have a high $\theta_{i}^{\prime}$ Гi.e. $\Gamma$ a high marginal cost of undertaking lobbying activities $\Gamma$ see Remark 1 below.

(iii) An equivalent ranking can be obtained by the following definition

$$
\beta_{i}=\frac{1}{\gamma_{i}}-1=\frac{P^{\prime} B^{\prime}(\hat{A})}{\theta_{i}^{\prime}\left(\hat{a}_{i}\right)}
$$

If $\beta_{j}>\beta_{i}$ then firm $j$ is said to have comparative advantage in lobbying. Note that $\beta_{j}>\beta_{i}$ if and only if $\gamma_{j}<\gamma_{i}$.

The following remarks are in order. From (??) the indicator $\gamma_{i}$ is defined using equilibrium values. It should be noted that

$$
\operatorname{sgn}\left[\gamma_{i}-\gamma_{j}\right]=\operatorname{sgn}\left[\theta_{i}^{\prime}\left(\hat{a}_{i}\right)-\theta_{j}^{\prime}\left(\hat{a}_{j}\right)\right]
$$

where sgn means 'the sign of'.Under Specification 3 (constant returns to monitoring) $\Gamma \gamma_{i}>\gamma_{j}$ if and only if $\delta_{i}>\delta_{j}$. Thus $\Gamma$ under constant returns to monitoring $\Gamma$ comparative advantage amounts to the same thing as absolute advantage.

We now present some results for the case of linear demand $\Gamma P=P^{0}-b Z$, where $P^{0}>0$ Tand $b>0$.

Proposition 3.1: Assume linear demand and increasing returns in monitoring (i.e. Tspecification 1). Then 
(a) at an interior Nash equilibrium of the lobbying game $\Gamma$ firms that are less efficient in monitoring in absolute terms (low $\delta_{j}$ ) will devote more entrepreneurial resources to monitoring $\Gamma$ and achieve lower cost and greater profit than other firms. Thus $\Gamma$ the availability of lobbying opportunities reverses the ranking of firms' profitability if the Nash equilibrium is interior.

(b) there may exist a corner solution which also has the property of profitability ranking reversal.

Proof:

(a) From (??) $\Gamma$ with $E_{d}=0$ because of linear demand $\Gamma$ we have at an interior equilibrium

$$
\theta_{i}^{\prime}\left(a_{i}\right)=\alpha \delta_{i} m_{i}^{\alpha-1}=\frac{P^{\prime} B^{\prime}}{k}=\theta_{j}^{\prime}\left(a_{j}\right)
$$

It follows that if $\delta_{i}>\delta_{j}>0$ then $\Gamma$ since $\alpha>1 \Gamma$

$$
\frac{m_{j}}{m_{i}}=\left[\frac{\delta_{i}}{\delta_{j}}\right]^{1 /(\alpha-1)}>1
$$

Therefore $\Gamma$ at the interior Nash equilibrium $\Gamma$

$$
c_{j}\left(m_{j}\right)=\bar{c}-\left[\frac{P^{\prime} B^{\prime}}{\alpha k}\right] m_{j}<c_{i}\left(m_{i}\right)
$$

This shows that if two firms $(i, j)$ have $\delta_{i}>\delta_{j}>0$ and $h_{i}=h_{j} \Gamma$ then $\Gamma$ in the absence of lobbying opportunities $\Gamma$ firm $i$ would have lower cost and thus higher profit than firm $j$ Tbut $\Gamma$ when lobbying opportunities become available $\Gamma$ at an interior Nash equilibrium $\Gamma$ firm $i$ will have higher cost and thus lower profit than firm $j$.

(b) To prove part (b) $\Gamma$ it suffices to provide a numerical example. Assume there are only two domestic firms. Let $P^{0}=100, \bar{c}=20 \Gamma b=1 \Gamma \alpha=2 \Gamma$ $\delta_{1}=2 \Gamma \delta_{2}=1 \Gamma h_{1}=h_{2}=5$. Assume that the function $B(A)$ takes the simple form: $B(A)=10(5-A)^{2}$ if $0 \leq A \leq 5$ and $B(A)=0$ if $A \geq 5$. Then the reaction functions of the lobbying game has the following properties. (See Figure 1.)

The reaction function of firm $1 \Gamma a_{1}=R_{1}\left(a_{2}\right)$ is given by: $R_{1}\left(a_{2}\right)=5$ if $a_{2}=0 \Gamma R_{1}\left(a_{2}\right)=5-5 a_{2}$ if $0 \leq a_{2} \leq 1$, and $R_{1}\left(a_{2}\right)=0$ if $a_{2}>1$.

The reaction function of firm $2 \Gamma a_{2}=R_{2}\left(a_{1}\right)$ is given by: $R_{2}\left(a_{1}\right)=5$ if $a_{1}=0 \Gamma R_{2}\left(a_{1}\right)=5-(5 / 3) a_{1}$ if $1 \leq a_{1} \leq 3$, and $R_{2}\left(a_{1}\right)=0$ if $a_{1}>3$.. 
There are three Nash equilibria. The first Nash equilibrium is an interior one $\Gamma$ with equilibrium values $\left(a_{1}, a_{2}\right)=(30 / 11 \Gamma 5 / 11)$. The second Nash equilibrium is $\left(a_{1}, a_{2}\right)=(5 \Gamma 0) \Gamma$ and the third Nash equilibrium is $\left(a_{1}, a_{2}\right)=(0 \Gamma 5)$. At the first two equilibria firm 1 earns less profit than firm $2 \Gamma$ which shows that their profit ranking is reversed. Note that the interior equilibrium in this two-firm example is unstable while the remaining two equilibria are stable. $\square$

The intuition behind Proposition 3.1 is as follows. If lobbying opportunities do not exist $\Gamma$ then $\Gamma$ other things being equal $\Gamma$ firms with a higher $\delta$ will have lower costs and therefore higher outputs and profits. When firms can lobby these large firms will tend to divert a lot of entrepreneurial resources to lobbying activities $\Gamma$ because they expect a large gain from the rise in price that accompanies tighter import quotas. Suppose there are just two domestic firms $\Gamma$ and firm 1 is more efficient in monitoring $\left(\delta_{1}>\delta_{2}\right)$. Then firm 1's marginal-cost-of-lobbying schedule $\Gamma \theta_{1}^{\prime}\left(a_{1}\right)$ is everywhere above that of firm 2 if $h_{1}$ is equal to or is not too different from $h_{2}$ (See Figure $2 \Gamma$ where $\theta_{1}^{\prime}(x)>\theta_{2}^{\prime}(x)$ for any common $x$.) These schedules are downward-sloping because $\alpha$ is greater than 1 . Firm $1 \Gamma$ anticipating that the equilibrium $\hat{a}_{2}$ is small (the hat denotes the equilibrium value) $\Gamma$ perceives correctly that its marginal-benefit-of-lobbying schedule is quite high. Therefore it sets a high $\hat{a}_{1}$. Firm 2 Cknowing that $\hat{a}_{1}$ is high perceives its marginal-benefit-of-lobbying schedule to be quite low $\Gamma$ so its low $\hat{a}_{2}$ is justified. The outcome is almost a free-ride for firm 2. (In the example given in part (b) of the proof $\Gamma$ this free ride for firm 2 occurs at the first two Nash equilibria but not at the third Nash equilibrium.)

For the case of decreasing returns in monitoring $\Gamma$ the profitability ranking is not reversed when lobbying opportunities are available:

Proposition 3.2: Assume linear demand and decreasing returns in monitoring (ieГspecification 2). Then Tat an interior Nash equilibrium are less efficient in monitoring in absolute terms (low $\delta_{j}$ ) will devote less entrepreneurial time to monitoring $\Gamma$ and achieve higher cost and lower profit than other firms.

Figure 3 illustrates Proposition 3.2.

Another interesting question is whether an increase in the number of firms will reduce the aggregate lobbying effort. The answer is given by Proposition 


\section{3 .}

Proposition 3.3: Assume that the demand function is linear $\Gamma P=a-b Z \Gamma$ and that all domestic firms are identical. Then an increase in the number of firms $\Gamma$ without changing the endowment $h_{i}$ of each firm $\Gamma$ will reduce aggregate lobbying effort if and only if $a \theta^{\prime \prime}(a) / \theta^{\prime}(a)<1$ (ie $\Gamma$ iff the elasticity of $\theta^{\prime}$ is less than 1).

Proof:

With linear demand and identical firms $\Gamma$ the first order condition (??) becomes

$$
-k \theta^{\prime}(A / k)-b B^{\prime}(A)=0
$$

This equation yields

$$
\frac{d A}{d k}=\frac{\theta^{\prime}-\theta^{\prime \prime} A / k}{\left[-\theta^{\prime \prime}-b B^{\prime \prime}\right]}
$$

where the denominator is negative because of (??) and $k \geq 1 \Gamma$ and the numerator is positive if $a \theta^{\prime \prime}(a) / \theta^{\prime}(a)<1$.

We now turn to the non-linear demand case. In this case it is convenient to make use of condition (??). The following proposition relates the comparative advantage in monitoring with equilibrium market shares and profits.

Proposition 3.4: Assume non-linear demand. Then at an interior Nash equilibrium $\Gamma$

(a) If the demand curve is locally concave $(E<0)$ Tthen firms that have greater comparative advantage in monitoring will have greater market shares and greater profits.

(b) If the demand curve is locally convex $(E>0)$ Tthen firms that have greater comparative advantage in monitoring will have smaller market shares and smaller profits. (In other words Tthe availability of lobbying opprtunities reverses the profit ranking.)

\section{Proof:}

From (??) $\Gamma$ with $E \neq 0 \Gamma$

$$
s_{i}-s_{j}=\frac{2\left(\gamma_{j}-\gamma_{i}\right)[k+1-s E]}{E}
$$

It follows that

$$
\operatorname{sgn}\left[s_{i}-s_{j}\right]=\operatorname{sgn}[-E] \operatorname{sgn}\left[\gamma_{i}-\gamma_{j}\right]
$$


that is $\Gamma s_{i}-s_{j}$ has the same sign as that of $\gamma_{i}-\gamma_{j}$ if $E<0$ Tand has opposite sign as that of $\gamma_{i}-\gamma_{j}$ if $E>0$. Finally $\mathrm{Cfrom}(? ?) \pi_{i}=\left[-P^{\prime}\right] q_{i}^{2}=\left[-P^{\prime}\right] Z^{2} s_{i}^{2}$.

In order to understand the intuition behind Proposition 3.4 $\Gamma$ we must explicate the role of $E$. The following lemma is useful for that purpose. (A similar result for the tariff case was independently proved by Collie $\Gamma 1993 \Gamma$ and Long and Soubeyran $\Gamma 1997$.

Lemma 3.1. If $E<0$ [respectively $E>0$ ] so that the demand curve is concave [respectively $\Gamma$ convex] $\Gamma$ then an exogenous reduction of import quota will expand the equilibrium output of lower cost domestic firms by more [respectively [by less] than that of higher cost domestic firms.

Proof:

Assume without loss of generality that firm $i$ has lower cost than firm $j$ $\left(c_{j}-c_{i}>0\right)$. From (??) and (??) $\Gamma$

$$
q_{i}-q_{j}=\frac{1}{\left[-P^{\prime}\right]}\left(c_{j}-c_{i}\right)
$$

and hence

$$
\frac{d}{d(-B)}\left[q_{i}-q_{j}\right]=\frac{1}{\left[-P^{\prime}\right]^{2}}\left(c_{j}-c_{i}\right) P^{\prime \prime}\left[\frac{\partial Z}{\partial(-B)}\right]
$$

which is positive if $E<0$.

It follows from Lemma 3.1 that if $E<0$ then lower cost firms have a stronger incentive to contribute to lobbying. They devote more resources to lobbying Twhile still maintaining lower production costs. Figure 4 illustrates the equilibrium when firm 1 has a comparative advantage in monitoring and $E<0$. Its marginal cost of lobbying $\Gamma \theta_{1}^{\prime}$ is therefore higher. If it expects $a_{2}$ to be small in equilibrium $\Gamma$ then its marginal benefit curve (as a function of $a_{1}$ ) is also high (recall that $E$ is negative) and in equilibrium its contribution to lobbying could be slightly more than that of firm $2 \Gamma$ without harming its cost ranking.

In the opposite case where $E>0 \Gamma$ all domestic firms still gain from lobbying but the higher cost firms expand more relative to the lower cost firms. One may ask why the lower cost firms do not pretend to be higher cost firms $\Gamma$ by contributing less to lobbying $\Gamma$ in order to gain more. The answer lies in the fact that they know if they were to do so aggregate lobbying $\Gamma$ which would be bad for everyone in the home industry. 
We now consider a very special case where all $\delta_{i}=\delta_{j}$ for all $i, j$ Tso that firms differ only with respect to endowments : $h_{i} \neq h_{j}$. In this case we obtain the following:

Proposition 3.5: If $\delta_{i}=\delta_{j}$ for a pair $i, j \Gamma$ so that these two firms differ only with respect to endowments $\Gamma$ then at a Nash equilibrium where both $i$ and $j$ contribute $\Gamma$ they must achieve the same market share and hence the same comparative advantage in monitoring if (i) $E<0$ and $r(m)$ is strictly concave or (ii) $E>0$ and $r(m)$ is strictly convex.

Proof:

Take the case $E<0$ and $r(m)$ strictly concave. Then from (??) and (??) $\Gamma$ if both firms contribute $\Gamma$ then $\operatorname{sgn}\left[s_{i}-s_{j}\right]=\operatorname{sgn}\left[\theta_{i}^{\prime}\left(\hat{a}_{i}\right)-\theta_{j}^{\prime}\left(\hat{a}_{j}\right)\right]$.

Suppose $s_{i} \neq s_{j}$. Say $s_{i}>s_{j}$. Then $\theta_{i}^{\prime}\left(\hat{a}_{i}\right)>\theta_{j}^{\prime}\left(\hat{a}_{j}\right)$, which is true if and only if $\delta r^{\prime}\left(h_{i}-\hat{a}_{i}\right)>\delta r^{\prime}\left(h_{j}-\hat{a}_{j}\right)$, if and only if $\hat{m}_{i}<\hat{m}_{j}$. This would imply $c_{i}>c_{j}$ and hence $s_{i}<s_{j} \Gamma$ a contradiction. It follows that $s_{i}=s_{j}$ if both firms contribute.

From Proposition 3.5 if two firms are identical except for a slight difference in endowments then at an interior equilibrium their contributions differ by exactly their difference in endowments. If their endowments greatly differ from each other $\Gamma$ it is likely that only one firm contributes while the other free rides.

\section{The Cooperative Case}

We now consider the case where firms coordinate their lobbying activities $\Gamma$ even though they are Cournot rivals in the product market. This specification is quite realistic Tand is consistent with the theory of semi-collusion (as exemplified by the by the works of Friedman and Thisse 1993ГFershtman and Gandal 1994 Nalebuff and Brandenburger 1996 LLong and Soubeyran 2000Г among others) $\Gamma$ which is based on the observation that firms often cooperate in some sphere while compete in other spheres.

The cooperative case is more complicated because in the first stage of the game there are incentive for firms to change the cost structure within the industry so as to reduce rivalry in the second stage. In other words $\Gamma$ allocation of lobbying efforts now serves two distinct purposes. The first purpose is to increase protection against foreign imports $\Gamma$ and the second 
purpose is to alter the composition or degree of concentration of the domestic industry. Coordination of lobbying may thus be seen as a surrogate for cooperation in the second stage (which is often prohibited by anti-trust laws). In fact $\Gamma$ as we will see below $\Gamma$ even if firms are ex-ante identical in technology and endowment $\Gamma$ their optimal coordination of lobbying effort may call for asymmetric contributions.

In order to handle these complicated issues $\Gamma$ we must find a relationship between aggregate profit of the domestic firms and their cost structure.

Recall that firm i's unit cost is

$$
\theta_{i}\left(a_{i}\right)=\bar{c}-r_{i}\left(h_{i}-a_{i}\right)
$$

It is convenient to define the inverse function

$$
a_{i}=a_{i}\left(r_{i}\right)
$$

where $r_{i}$ is now real number representing the reduction in unit cost below the maximum level $\bar{c}$. Let $r_{K}$ denote the mean reduction in unit cost:

$$
r_{K} \equiv \frac{1}{k} \sum_{i \in K} r_{i}
$$

The sum of the unit costs is:

$$
C=k\left(\bar{c}-r_{K}\right)
$$

Recall that the equilibrium quantity is $Z=B+Q(B, C)$, where $B=$ $B(A)$. This can now be written as

$$
Z=Z\left(A, k\left(\bar{c}-r_{K}\right)\right)
$$

The sum of the equilibrium profits of the domestic firms is

$$
\Pi=\sum_{i \in K} \pi_{i}=\frac{k\left\{P-\bar{c}+r_{K}\right\}^{2}}{\left[-P^{\prime}\right]}+\frac{1}{\left[-P^{\prime}\right]} \sum_{i \in K}\left(r_{i}-r_{K}\right)^{2}
$$

(for a proofTsee Long and Soubeyran 1996). This formula indicates that for a given $A$ and a given $r_{K}$ (so that both $P$ and $P^{\prime}$ are fixed) industry profit can be increased by increasing the variance $V$ of the cost reduction $\Gamma$ where

$$
V \equiv \frac{1}{k} \sum_{i \in K}\left(r_{i}-r_{K}\right)^{2}
$$


To illustrate this possibility $\Gamma$ consider the case where $r_{i}\left(m_{i}\right)=\delta_{i} m_{i}^{\alpha}=$ $\delta_{i}\left(h_{i}-a_{i}\right)^{\alpha} \Gamma$ with $\alpha>1$ Then the function $a_{i}\left(r_{i}\right)$ is convex:

$$
a_{i}\left(r_{i}\right)=h_{i}-\left[\frac{r_{i}}{\delta_{i}}\right]^{1 / \alpha}
$$

Summing over all $i$ एwe obtain

$$
\sum_{i \in K}\left[\frac{r_{i}}{\delta_{i}}\right]^{1 / \alpha}=\sum_{i \in K} h_{i}-A
$$

For a given $A$ and a given $r_{K} \Gamma$ the set of feasible $\left(r_{1}, \ldots, r_{k}\right)$ is illustrated in Figure 5 for the case $k=2$. The reader can also visualize the feasible set for the case $k=3 \Gamma$ where clearly the optimal solution to the problem of maximizing $\Pi$ in (??) subject to a given $A$ and a given $r_{K}$ is asymmetric. This result on asymmetric contributions is stated as Proposition 4.1:

\section{Proposition 4.1 (Asymmetric contributions)}

In the cooperative lobbying case $\Gamma$ firms may have incentive to agree on asymmetric contributions even when they are ex-ante identical.

In the case of constant returns to monitoring Tan asymmetric solution will also typically arise. It suffices to illustrate this result for the case of two firms and linear demand $\Gamma P(Z)=\bar{P}-Z$. We now show that for any given aggregate amount $A<\max \left\{h_{1}, h_{2}\right\}$ devoted to lobbying $\Gamma$ given Cournot competition in stage 2 Tindustry profit is maximized in stage 1 by having all the lobbying done by only one firm. The proof is as follows. Given $A \Gamma$ the equilibrium price under Cournot rivalry is $\widehat{P}=(1 / 3)\left[\bar{P}-B(A)-\theta_{1}\left(a_{1}\right)-\theta_{2}\left(a_{2}\right)\right] \Gamma$ where $\theta_{1}\left(a_{1}\right)=\bar{c}-\delta_{1}\left(h_{1}-a_{1}\right)$ and $\theta_{2}\left(a_{2}\right)=\bar{c}-\delta_{2}\left(h_{2}-a_{2}\right)$ where $a_{2}=A-a_{1} \geq 0$. Total profit $\Gamma$ for a given $A \Gamma$ is $\left[\widehat{P}-\theta_{1}\right]^{2}+\left[\widehat{P}-\theta_{2}\right]^{2} \equiv \Pi\left(a_{1}\right)$. This expression is strictly convex in $a_{1}$. Maximizing $\Pi\left(a_{1}\right)$ with respect to $a_{1}$ subject to $a_{1} \geq 0$ and $A-a_{1} \geq 0$ results in a corner maximum.

In an asymmetric contribution cooperative equilibrium $\Gamma$ some firms may be asked not to contribute to lobbying activities. These firms will earn more profits than others $\Gamma$ in the case of ex-ante identical firms. We do not specify in this paper how the aggregate industry profit is to be distributed among firms. A possible approach is to assume that firms make side transfers to each others 5 so that no firm will envy other firms. Such an approach has 
been formalized in Long and Soubeyran (1999) in the context of formation of a research joint-venture by rival oligopolists $\Gamma$ where it is also demonstrated that contributions to a research joint venture may be asymmetric.

In what follows $\Gamma$ we characterize the optimal provision of the non-pure public good. While equation (??) was useful for showing the intuition behind the asymmetric contribution result $\Gamma$ whenever the focus is on interior solutions $\Gamma$ it is more convenient to return to the original approach where the $a_{i}$ 's are treated as direct choice variables. Industry profit is then

$$
\Pi=\sum_{i \in K} \pi_{i}=\frac{1}{\left[-P^{\prime}(Z(a))\right]} \sum_{i \in K}\left[P(Z(a))-\theta_{i}\left(a_{i}\right)\right]^{2}
$$

As shown in Appendix $2 \Gamma$ differentiating (??) with respect to $a_{j}$ gives the following first order condition for an interior solution for the variable $a_{j}$ :

$$
\frac{\partial \Pi}{\partial a_{j}}=\frac{Z(2 s-E H)\left[P^{\prime}(Z) B^{\prime}(A)+\theta_{j}^{\prime}\right]}{k+1-E_{d}}-2 q_{j} \theta_{j}^{\prime}=0
$$

where $H$ is the Herfindahl index of concentration $\Gamma$ defined as

$$
H \equiv \sum_{i \in K} s_{i}^{2}=\sum_{i \in K}\left[\frac{q_{i}}{Z}\right]^{2}
$$

and it can be verified that

$$
H \leq\left[\frac{Q}{Z}\right]^{2} \equiv s^{2}
$$

where $Q \equiv \sum_{i \in K} q_{i}$.Using (??) we obtain the (generalized) Samuelsonian rule of optimal provision of a non-pure public good

$$
\frac{\left[\frac{\partial Z}{\partial a_{i}}\right]}{\left[\frac{\partial Z}{\partial a_{j}}\right]}=\frac{q_{i} \theta_{i}^{\prime}}{q_{j} \theta_{j}^{\prime}}
$$

This Ttogether with the equilibrium conditions of the Cournot game in the second stage of the game $\Gamma$

$$
\widehat{q}_{i}=\frac{\widehat{P}-\theta_{i}}{\left[-P^{\prime}\right]}
$$

determine the optimal vector $\left(a_{1}, \ldots, a_{k}\right)$. 
To illustrate $\Gamma$ consider for simplicity $\Gamma$ the case of linear demand $\Gamma$ with $P(Z)=\bar{P}-Z$ Cand just two domestic firms $\Gamma$ with $\theta_{i}=\bar{c}-\delta_{i}\left(h_{i}-a_{i}\right)^{\alpha}$ where $h_{1}=h_{2}=h \Gamma 0<\alpha<1 \Gamma$ and $\delta_{1}>\delta_{2}>0$ Then (??) reduces to

$$
\frac{2 Q}{3}\left[\alpha \delta_{i}\left(h_{i}-a_{i}\right)^{\alpha-1}-B^{\prime}\left(a_{1}+a_{2}\right)\right]-2 \widehat{q}_{i} \alpha \delta_{i}\left(h_{i}-a_{i}\right)^{\alpha-1}=0, \quad i=1,2 .
$$

where $\widehat{q}_{i}=\widehat{P}-\bar{c}+\delta_{i}\left(h_{i}-a_{i}\right)^{\alpha}$ and $\widehat{P}=(1 / 3)\left[\bar{P}-B(A)-\theta_{1}-\theta_{2}\right]$. It can be verified that $\widehat{q}_{1}>\widehat{q}_{2}$ and $a_{1}<a_{2}$.

The above example shows that at an interior solution $\Gamma$ firms with greater absolute advantage in monotoring will be asked to contribute less resources to political activities. The intuition is as follows. For any given total amount of industry lobbying $\Gamma A \Gamma$ the size of the quota is determined. Therefore the burden of $A$ should be distributed among domestic firms in such a way that $\Gamma$ given $B(A) \Gamma$ the domestic industry's profit is maximized $\Gamma$ given that the domestic firms are Cournot rivals in stage 2. But from (??) Tindustry profit is increasing in the variance of cost reduction. Therefore $\Gamma$ firms with absolute advantage in monitoring will be asked to contribute less $a_{i}$ so that they become relatively bigger. This is due to the productive efficiency consideration.

We now ask the following question: does more heterogeneity among domestic firms lead to more protection? The answer turns out to depend on the curvature of the demand curve. Recall that Lemma 3.1 says that if the demand curve is convex $(E>0) \Gamma$ then a given reduction in import quota tends to have an equalizing effect on firms's sizes (i.e. $\Gamma$ the big firms will expand by less than the smaller firms.) Therefore the marginal gain in domestic industry's profit $\Gamma$ caused by an increase in $A \Gamma$ is relatively low. This means that the industry will not spend much on lobbying. This effect will be mitigated $\Gamma$ however $\Gamma$ if firms are ex-ante sufficiently different. Thus we would expect that if $E$ is positive $\Gamma$ then $A$ will be greater $\Gamma$ the greater is the heterogeneity among firms. Now the Herfindahl index $H$ is a measure of heterogeneity: given the number of firms $\Gamma$ this index is smallest when firms are identical. Our reasoning indicates that $\Gamma$ if $E$ is positive $\Gamma$ there would be a positive correlation between $H$ and the size of the domestic industry's market share. The following calculation confirms our intuition. Summing (??) over all firms $\Gamma$ we obtain

$$
2 s\{s E-k-1\}+2 s(k+\beta)=(m+\beta) E H
$$


where $\beta \equiv \sum_{i \in K} \beta_{i}$. Assume $E \neq 0$ then we obtain from (??):

$$
s^{2}+\frac{(\beta-1) s}{E}-\frac{1}{2}(\beta+k) E H=0
$$

If $E>0$ Tthen the above quadratic equation in $s$ has two roots of opposite signs $^{9}$. Since $s$ must be non-negative $\Gamma$ we take the positive root

$$
s=-\frac{1}{2}\left[\frac{\beta-1}{E}\right]+\frac{1}{2} \sqrt{\left[\frac{\beta-1}{E}\right]^{2}+2(k+\beta) E H}
$$

This equation shows that $\Gamma$ if $E>0$ then the share of imports in domestic consumption $\Gamma B / Z=1-s$ is negatively correlated with the Herfindahl index of concentration of the domestic industry. This result should be interpreted with care because $H$ and $\beta$ are both endogenous.

Proposition 4.2: Assume $E>0$. Then the share of imports in domestic consumption tend to be inversely related to the degree of concentration of the domestic industry.

\section{Conclusion}

We have shown that in an asymmetric oligopoly where domestic firms allocate entrepreneurial time between lobbying for protection and internal control (monitoring) $\Gamma$ the availability of lobbying opportunity may have differential effects on the profit of individual firms. In fact Tunder non-cooperative lobbying $\Gamma$ the ranking of profits will be reversed when lobbying becomes possible $\Gamma$ if the monitoring technology exhibits increasing returns $\Gamma$ or if the demand curve is locally convex. Such reversal may be attributed to free riding in a non-cooperative equilibrium. In the cooperative lobbying case $\Gamma$ by definition there is no free riding. In this case the optimal allocation of lobbying effort entirely reflects the motive of reducing aggregate production cost. Our model also lends only limited support to the conventional wisdom that industries with greater concentration tend to obtain more protection. In our model $\mathrm{Cit}$ is assumed that firms lobby for quantitative import restrictions $\Gamma$ such as an

\footnotetext{
${ }^{9}$ If $E<0$, we either have two real roots of the same sign or two complex roots. In the first case, any root with $s>1$ should be excluded. The second case would indicate that the assumption that all firms have an interior solution $h_{i}>a_{i}>0$ is not valid.
} 
aggregate quota. Similar results can also be obtained in a model where firms lobby for tariff protectionГsee Hillman et al. (2000).

In this paper whether firms cooperate or not is taken as exogenous. But our results on profit reversal points strongly to the possibilily of developing a theory of endogenous coalition formation in the lobbying game. Such a theory would have a flavor similar to that of the theory of endogenous vertical integration ${ }^{10}$.

\section{APPENDIX}

\section{APPENDIX 1: Proof of (??)}

Let $C=C_{-i}+c_{i}\left(m_{i}\right)$. Differentiating (??) with respect to $m_{i}$ yields

$$
\frac{\partial \pi_{i}}{\partial m_{i}}=\frac{\left[P-c_{i}\right]\left[\left(2-s_{i}\right) E_{d}-2 k\right]}{\left[-P^{\prime}\right]\left(k+1-E_{d}\right)} c_{i}^{\prime}\left(m_{i}\right)
$$

This derivative is positive if $E<2 k /\left(2-s_{i d}\right)$ Tie $\Gamma$ if the demand curve is not too convex.

\section{APPENDIX 2: Proof of (??)}

From (??) $\Gamma$

$$
\frac{\partial \Pi}{\partial a_{j}}=2 \sum_{i \in K}\left[\frac{P-c_{i}}{\left[-P^{\prime}\right]}\right] P^{\prime}(Z) \frac{\partial Z}{\partial a_{j}}-\frac{2\left(P-c_{j}\right) \theta_{j}^{\prime}}{\left[-P^{\prime}\right]}+\sum_{i \in K}\left[\frac{P-c_{i}}{\left[-P^{\prime}\right]}\right]^{2} P^{\prime \prime}(Z) \frac{\partial Z}{\partial a_{j}}
$$

The proof is completed by noting the facts that $\frac{P-c_{i}}{\left[-P^{\prime}\right]}=q_{i}$ and that

$$
\frac{\partial Z}{\partial a_{j}}=\frac{P^{\prime} B^{\prime}+\theta_{j}^{\prime}}{\left[-P^{\prime}\right]\left[E_{d}-k-1\right]}
$$

\section{APPENDIX 3: the case where the total resources are not con- strained.}

We now show that the main results in the text remain essentially unchanged if the $h_{i}$ s are not fixed $\Gamma$ but instead they can be obtained at a $\operatorname{cost} \Gamma$ provided that the marginal cost of obtaining $h_{i}$ are rising. In this case $\Gamma$ the expression (??) in the text must be interpreted as gross profit $\Gamma$ and net profit is define as

$$
\tilde{\pi}_{i}=\pi_{i}-\Omega_{i}\left(h_{i}\right)
$$

\footnotetext{
${ }^{10}$ See Gaudet and Long (1996) for a model of endogenous vertical integration.
} 
where $\Omega_{i}\left(h_{i}\right)$ is the cost of obtaining $h_{i}$.

It is convenient to define

$$
\theta_{i}\left(a_{i} ; h_{i}\right) \equiv \bar{c}-r_{i}\left(h_{i}-a_{i}\right)
$$

and $\Gamma$ with a slight abuse of notation $\Gamma$ we write

$$
\theta_{i}^{\prime}\left(a_{i} ; h_{i}\right)=\frac{\partial \theta_{i}}{\partial a_{i}}=r_{i}^{\prime}\left(m_{i}\right)
$$

We interpret $\theta_{i}^{\prime}\left(a_{i} ; h_{i}\right)$ as the marginal cost of lobbying $\Gamma$ because it measures the increase in production cost when resources are diverted away from monitoring. Let $a=\left(a_{1}, \ldots, a_{k}\right)$ and $h=\left(h_{1}, \ldots, h_{k}\right)$. Then $\Gamma$ with a slight abuse of notation $\Gamma Z=Z(a, h)$. From (??) $\Gamma$ firm $i$ 's net profit in stage 2 is

$$
\pi_{i}^{n e t}=\frac{\left[P(Z(a, h))-\theta_{i}\left(a_{i} ; h_{i}\right)\right]^{2}}{\left[-P^{\prime}(Z(a, h))\right]}-\Omega_{i}\left(h_{i}\right)
$$

To find firm $i$ 's optimal choice of $a_{i}$ and $h_{i}$ Tgiven the $a_{j}$ 's and $h_{j}(j \neq i) \Gamma$ we maximize (??) subject to the constraints $h_{i}-a_{i} \geq 0$ and $a_{i} \geq 0$. Write the Lagrangian

$$
L=\pi_{i}^{n e t}+\zeta_{i}\left[h_{i}-a_{i}\right]+\mu_{i} a_{i}
$$

The first order conditions are

$$
\frac{\partial L}{\partial a_{i}}=\Gamma_{i} r_{i}^{\prime}\left(m_{i}\right)+\Lambda_{i}-\zeta_{i}+\mu_{i}=0
$$

and

$$
\frac{\partial L}{\partial h_{i}}=-\Gamma_{i} r_{i}^{\prime}\left(m_{i}\right)-\Omega_{i}^{\prime}\left(h_{i}\right)+\zeta_{i}=0
$$

where

$$
\Gamma_{i} \equiv \frac{\partial \pi_{i}^{n e t}}{\partial Z} \frac{\partial Z}{\partial C}+\frac{\partial \pi_{i}^{n e t}}{\partial c_{i}}=\frac{\left(P-c_{i}\right)\left[E_{d}\left(2-s_{i d}\right)-2 k\right]}{\left[-P^{\prime}\right]\left(k+1-E_{d}\right)}<0
$$

and

$$
\Lambda_{i} \equiv \frac{\partial \pi_{i}^{n e t}}{\partial Z} \frac{\partial Z}{\partial B} B^{\prime}=\frac{\left(P-c_{i}\right)\left(2-s_{i d} E_{d}\right) P^{\prime} B^{\prime}}{\left[-P^{\prime}\right]\left(k+1-E_{d}\right)}>0
$$

We will focus on the case of an interior maximum. Then (??) gives

$$
\theta_{i}^{\prime}\left(a_{i} ; h_{i}\right)=\frac{\left[2-s_{i d} E_{d}\right] B^{\prime} P^{\prime}}{\left[2 k-E_{d}\left(2-s_{i d}\right)\right]}
$$


(note that both $2-s_{i d} E_{d}$ and $2 k-E_{d}\left(2-s_{i d}\right)$ are positive $\Gamma$ by (??) and (??).) The condition (??) has an intuitive interpretation: at an interior maximum $\Gamma$ an increase in the amount of resources devoted to lobbying will increase production cost by $\theta_{i}^{\prime} \Gamma$ ( this is the marginal cost of lobbying) and this must be balanced by the marginal gain from lobbying $\Gamma$ which consists of an increase in price (modified for factors such as market share $\Gamma$ and the effect of a price rise on revenue) brought about by a decrease in the import quota. If the maximum occurs at a corner $\Gamma$ we must have $\Gamma$ in the case of zero contribution to lobbying $\Gamma \theta_{i}^{\prime}\left(0 ; h_{i}\right)$ exceeds the marginal gain (the right-hand side of (??)); or $\Gamma$ in the case of zero monitoring $\Gamma a_{i}=h_{i}>0 \Gamma r_{i}^{\prime}(0)$ is smaller than the marginal gain from lobbying.

An interior maximum also implies

$$
-\Gamma_{i} r_{i}^{\prime}\left(h_{i}-a_{i}\right)=\Omega_{i}^{\prime}\left(h_{i}\right)
$$

This condition says that the marginal increase in gross profit obtained from increased monitoring must be equated to the marginal cost of obtaining resources for monitoring.

The second order conditions for an interior maximum are

$$
\frac{\partial^{2} L}{\left(\partial a_{i}\right)^{2}} \leq 0, \frac{\partial^{2} L}{\left(\partial h_{i}\right)^{2}} \leq 0, \frac{\partial^{2} L}{\left(\partial a_{i}\right)^{2}} \frac{\partial^{2} L}{\left(\partial h_{i}\right)^{2}} \geq\left[\frac{\partial^{2} L}{\partial a \partial h_{i}}\right]
$$

In the case of linear demand $\Gamma$ with $P=a-b Z$ Tthe first two of these conditions reduce to

$$
k r_{i}^{\prime \prime}\left(h_{i}-a_{i}\right)-b B^{\prime \prime}(A) \leq 0
$$

and

$$
\frac{2 k^{2}\left(r_{i}^{\prime}\right)^{2}}{b(k+1)^{2}}+\frac{2 k\left(P-c_{i}\right) r_{i}^{\prime \prime}}{b(k+1)}-\Omega_{i}^{\prime \prime}\left(h_{i}\right) \leq 0
$$

Condition (??) is satisfied if $r_{i}^{\prime \prime}$ is negative or not too positive Tand condition (??) is satisfied if $\Omega^{\prime \prime}\left(h_{i}\right)$ is a sufficiently great positive number $\Gamma$ or if $r_{i}^{\prime \prime}$ is sufficiently negative.

The following lemma will be useful:

Lemma A.1: If two firms $i$ and $j$ both have interior solutions $\Gamma$ then the following relationship must hold:

$$
\frac{q_{i}\left[\left(q_{i} / Q\right) E_{d}-2\right]}{q_{j}\left[\left(q_{j} / Q\right) E_{d}-2\right]}=\frac{\Omega_{i}^{\prime}\left(h_{i}\right)}{\Omega_{j}^{\prime}\left(h_{j}\right)}
$$


Proof: From (??) and (??) we obtain

$$
\frac{\Lambda_{i}}{\Lambda_{j}}=\frac{\Omega_{i}^{\prime}\left(h_{i}\right)}{\Omega_{j}^{\prime}\left(h_{j}\right)}
$$

Use this and (??) to obtain (??).

Remark: In the special case where $\Omega_{i}$ and $\Omega_{j}$ are linear and have the same slope (e.g. when firms face a perfect capital market) $\Gamma$ then (??) implies that $q_{i}=q_{j}$ if both firms have interior solution $0<a_{t}<h_{t} \Gamma t=1,2$. Thus $\Gamma$ in this special case $\Gamma$ firms would achieve the same cost reduction lobbying decision and the cost reduction decision become separable under perfect capital market conditions. We will focus on the case of imperfect capital market. The proofs of the following propositions are straightforward $\Gamma$ and will be omitted.

Proposition 3.1 A: If the functions $\Omega_{j}\left(h_{j}\right)$ are strictly convex $\Gamma$ then Proposition 3.1 in the text remains valid .

Remark: the proof is similar to that of Proposition 3.1 except that the $h_{i}$ are now determined endogenously by the conditions

$$
\frac{\Omega_{i}^{\prime}\left(h_{i}\right)}{\Omega_{j}^{\prime}\left(h_{j}\right)}=\frac{P-\bar{c}+\delta_{i} m_{i}^{\alpha}}{P-\bar{c}+\delta_{j} m_{j}^{\alpha}}
$$

Note the importance of the strict convexity assumption on the $\Omega_{j}($.$) func-$ tions. If these functions were linear and identical $\Gamma$ then an interior solution is not possible $\Gamma$ because it would imply both $m_{j} / m_{i}=\left(\delta_{i} / \delta_{j}\right)^{1 / \alpha}$ and $m_{j} / m_{i}=\left(\delta_{j} / \delta_{i}\right)^{1 /(1-\alpha)}$.

Proposition 3.2 A: If the functions $\Omega_{j}\left(h_{j}\right)$ are strictly convex $\Gamma$ then Proposition 3.2 in the text remains valid. In addition $\Gamma$ if $\Omega_{j}()=.\Omega_{i}($.$) for$ all $i, j$ then it can be shown that $\delta_{i}>\delta_{j}$ implies $h_{i}^{*}>h_{j}^{*}$.

Proposition 3.3 A: If the functions $\Omega_{j}\left(h_{j}\right)$ are strictly convex $\Gamma$ and $\Omega_{j}()=.\Omega_{i}($.$) for all i, j$. Tthen Proposition 3.3 in the text remains valid $\Gamma$ with the words "without changing the endowments $h_{i}$ of each firm" replaced by "without changing the functions $\Omega_{i}($.$) for all i$."

Proposition 3.4 A: If the functions $\Omega_{j}\left(h_{j}\right)$ are strictly convex $\Gamma$ then Proposition 3.4 in the text remains valid $\Gamma$ and we also have the following additional conditions to determine the equilibrium $h_{i}^{*}$ :

$$
q_{i}\left[\frac{q_{i} E_{d}}{Q}-2\right]\left[\frac{P^{\prime} B^{\prime}}{E_{d}-k-1}\right]=\Omega_{i}^{\prime}\left(h_{i}\right), \quad i \in K .
$$




\section{References}

[1] BaldwinГR. E. $1984 \Gamma$ Trade policies in developed countries $\Gamma$ in R. W. Jones and P. Kenen Teds $\Gamma H a n d b o o k$ of International Economics $\Gamma$ Volume I (North-HollandГAmsterdam).571-619.

[2] BergstromГТ.ГL. Bloom and H. VarianГ1986ГOn the private provision of public goods 5 Journal of Public Economics 29Г25-49.

[3] BesterГH. and M. HellwigГ1987ГMoral hazard and equilibrium credit rationing: an overview of the issues $\Gamma$ in $\mathrm{G}$. BambergГed.ГAgency Theory $\Gamma$ InformationTand Incentives (Springer Verlag NNew York) 135-166.

[4] CassingГJ.Г1996ГProtectionist mutual fundsГEuropean Journal of Political Economy $12 \Gamma 1-18$

[5] CollieГD.П1993ГStrategic trade policy under asymmetric oligopolyГ European Journal of Political Economy 9Г275-280.

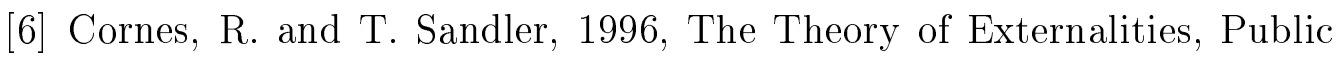
GoodsTand Club Goods (Cambridge University Press NNew York).

[7] DixitГ А.Г 1986Г Comparative statics for oligopolyГ International Economic Review 27Г107-122.

[8] Fershtman C C. and N. Gandal $1994 \Gamma$ Disadvantageous semi-collusion $\Gamma$ International Journal of Industrial Organization 12Г141-14.

[9] FriedmanГ J. and J. Thisse $Г$ 1993Г Partial collusion fosters minimum product differentiation $\Gamma$ Rand Journal of Economics 24Г631-645.

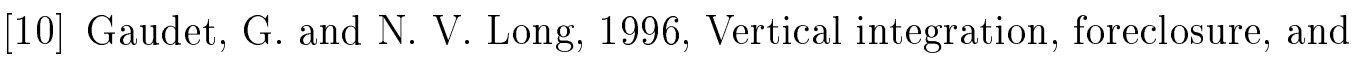
profits ГJournal of Economics and Management Strategy 5Г409-432.

[11] Globe and MailГ1999ГCanada's air war against BrazilГMarch 11Г1999Г Toronto.

[12] Golberg P. K. and G. MaggiГ 1999Г Protection for sale: an empirical investigation $\Gamma$ American Economic Review 89Г1135-55. 
[13] GrossmanГG. and E. HelpmanГ1994ГProtection for saleГAmerican Economic Review 84Г833-850 Treprinted in J. Bhagwati and P. RosendorffT eds. 1998 Readings in the Political Economy of Trade Policy (MIT Press CambridgeГMass).

[14] HellwigГМ.Г1989Г Asymmetric informationГfinancial markets $\Gamma$ and financial institutions: where are we currently going? European Economic Review 33Г277-85.

[15] HillmanГA. L.Г1982ГDeclining industries and political-support protectionist motives $\Gamma$ American Economic Review 72Г 1180-1187Г reprinted in J. Bhagwati and P. RosendorffTeds.[1998ГReadings in the Political Economy of Trade Policy (MIT Press C CambridgeГMass.)

[16] HillmanГA. L.Г1989ГThe Political Economy of Protection (Harwood Academic PublishersTCambridgeГLondon).

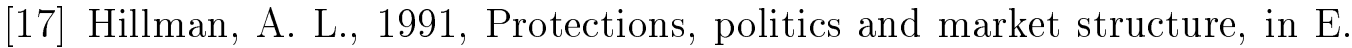
Helpman and A. Razin Teds. International Trade and Trade Policy (MIT Press Cambridge CMass).

[18] Hillman A. L. and H. W. Ursprung $\Gamma 1988 \Gamma$ Domestic politics $\Gamma$ foreign interests and international trade policyГAmerican Economic Review178 $\Gamma$ 729-745 Treprinted in J. Bhagwati and P. RosendorffГeds.I1998ГReadings in the Political Economy of Trade Policy (MIT Press CCambridgeГMass.)

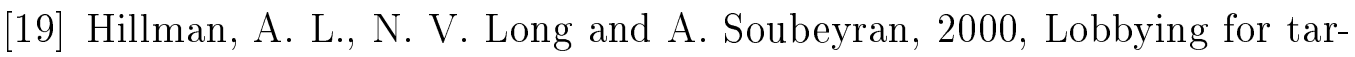
iff and allocations of entrepreneurial resources $\Gamma$ Working Paper 1-2000, McGill University.

[20] KempГ М. С.Г 1984Г A note on the theory of international transfers $\Gamma$ Economics Letters 14Г259-62.

[21] Long $\Gamma$ N. V. and A. Soubeyran $\Gamma 1996 \Gamma$ Lobbying for protection by heterogenous firms European Journal of Political Economy 12Г19-32.

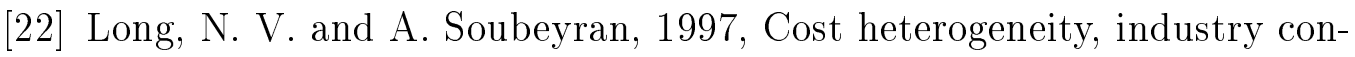
centration $\Gamma$ and strategic trade policy $\Gamma$ Journal of International Economics $43 \Gamma 207-220$. 
[23] Long $\Gamma \mathrm{N}$. V.and A. Soubeyran $1999 \Gamma$ Asymmetric contributions to research joint ventures $\Gamma$ Japanese Economic Review 50Г122-137.

[24] Long $\Gamma$ N. V. and A. Soubeyran $\Gamma 2000 \Gamma$ Cost manipulation games in oligopoly $\Gamma$ with costs of manipulating $\Gamma$ International Economic Review $\Gamma$ forthcoming.

[25] MageeГS. P.Г1994ГThe political economy of trade policyГin D. Greenaway and L. A.WintersTeds. $\Gamma$ Surveys in International Trade (Blackwell Oxford) 139-176.

[26] MayerГW.Г 1998ГTrade policy platforms of competing parties: What makes them different? Review of International Economics 6Г185-203.

[27] MilneГF.Г1975ГDefault risk and corporate leverageГJournal of Financial Economics $2 \Gamma 165-85$.

[28] MitraГD.Г1999ГEndogenous lobby formation and endogenous protection: a long-run model of trade policy determination $\Gamma$ American Economic Review 89, 1116-34.

[29] NalebuffTB. J. and A. M. BrandenburgerГ1996ГCo-opetition (Bentam Doubleday Dell Publishing groupГDoubleday).

[30] NitzanГS. I.Г1994ГModeling rent seeking contestsГEuropean Journal of Political Economy 10Г41-60

[31] OlsonГM. Jr.Г1965ГThe Logic of Collective Action: Public Goods and the Theory of Groups (Harvard University Press $\Gamma$ CambridgeГMass.)

[32] Potters Г J. and R. Sloof 1996 Interest groups: A survey of empirical models that try to assess their influenceГEuropean Journal of Political Economy 12Г403-442.

[33] PottersГJ.ГR. SloofTand F. van WindenГ1997ГCampaign expenditures $\Gamma$ contributions $\Gamma$ and direct endorsements: the strategic use of information and money to influence voter behaviorГEuropean Journal of Political Economy13Г1-31.

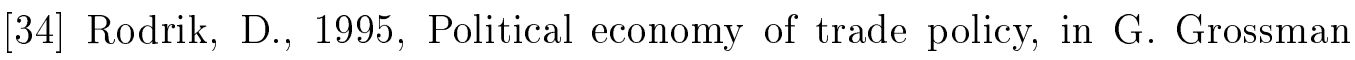
and K. RogoffГeds.ГHandbook of International Economics $\Gamma$ Volume 3 (North-HollandГAmsterdam)1457-1495. 
[35] SandlerГТ.Г1992ГCollective Action: Theory and Applications (University of Michigan Press $\Gamma$ Ann Arbor).

[36] StiglerГG.Г1964ГA theory of oligopolyГ Journal of Political EconomyГ reprinted in O. WilliamsonГed. $1990 \Gamma$ Industrial Organization (Elgar $\Gamma$ Aldershoot $\Gamma \mathrm{UK}) \Gamma 71-88$.

[37] UrsprungГ Н. W.Г 1990Г Public goods $\Gamma$ rent dissipation $\Gamma$ and candidate competition $Г$ Economics and PoliticsL2Г115-132.

[38] VousdenГN. and N. CampbellГ1994ГThe organizational costs of protectionГJournal of International Economics 40Г219-238.

[39] WarrГР. 1983ГThe private provision of public goods is independent of the distribution of incomeГEconomics Letters 13Г207-211. 
Figure 1

Multiple Equilibria

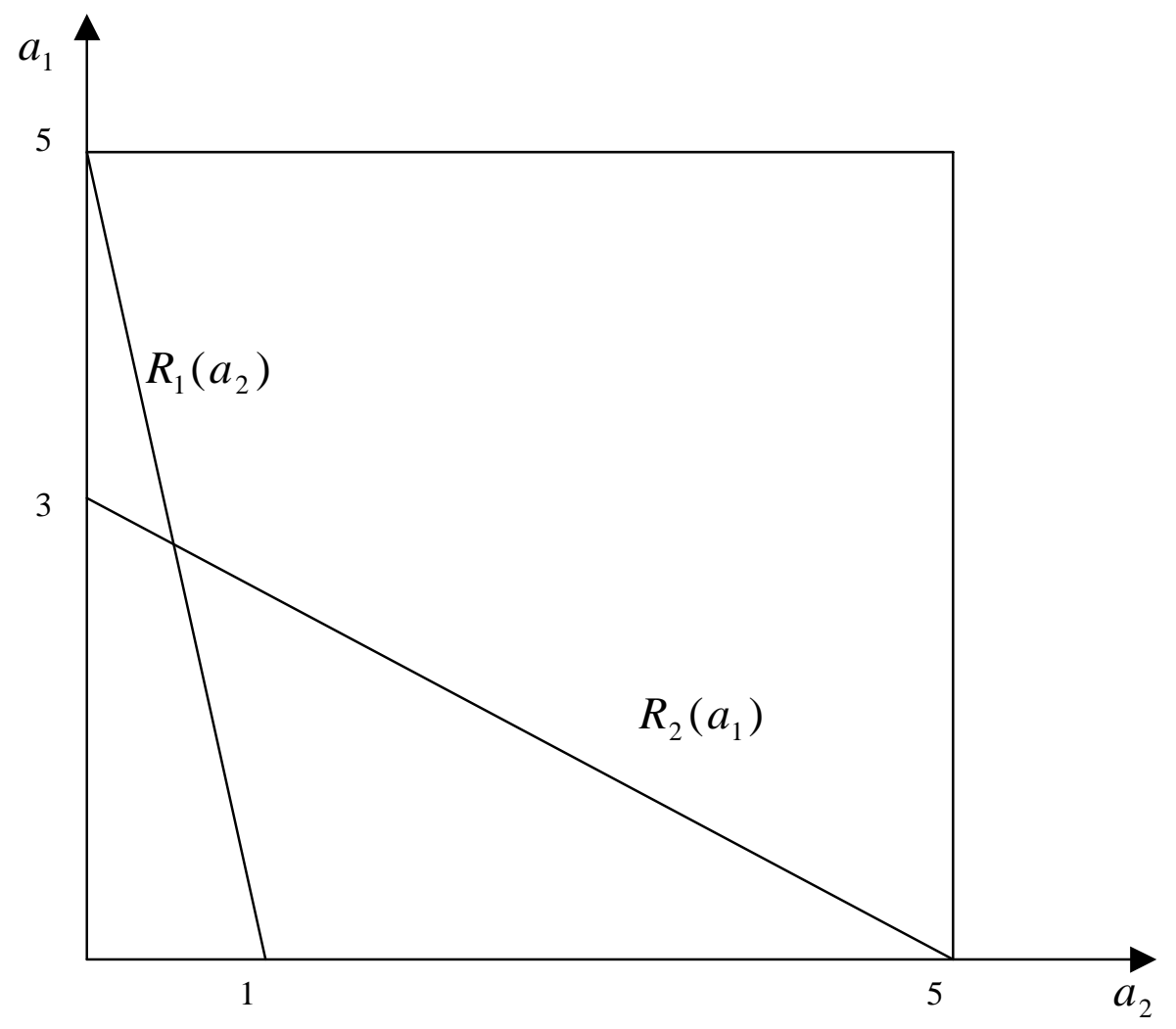


Figure 2

The Case: $E=0, \delta_{1} \geq \delta_{2}$, and Increasing Return to Monitoring

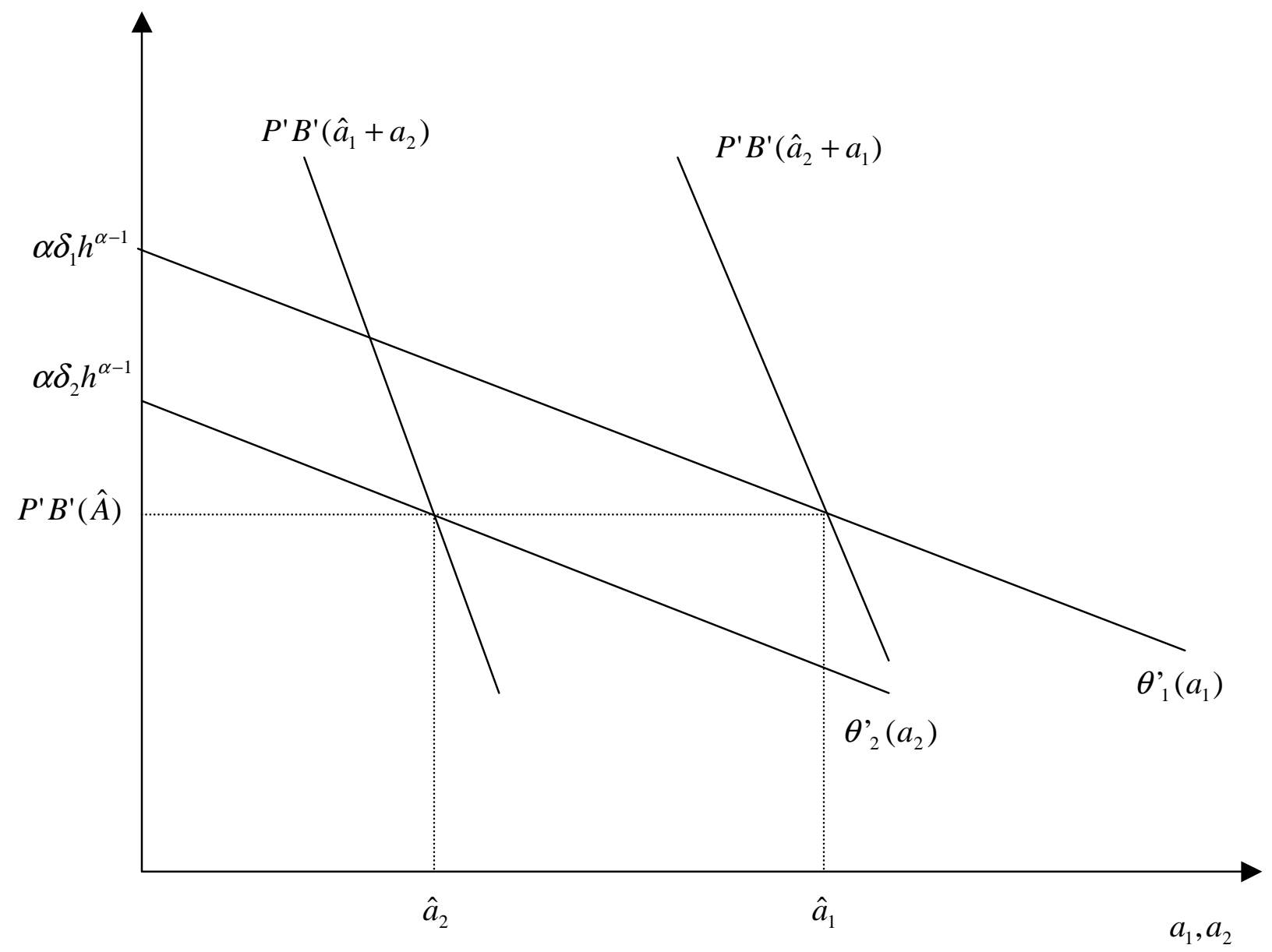


Figure 3

The Case: $E=0, \delta_{1} \geq \delta_{2}$, and Decreasing Return to Monitoring

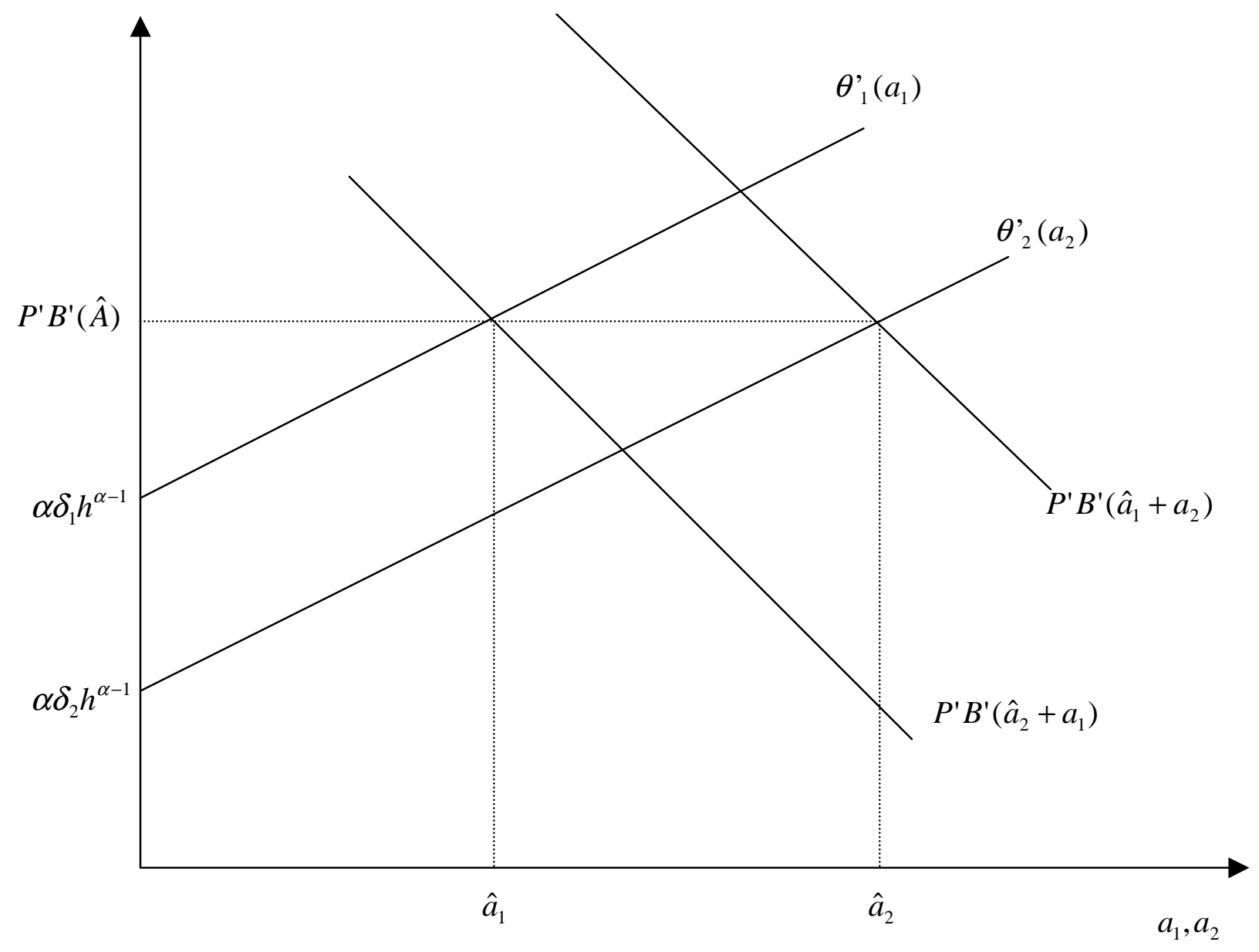


Figure 4

The Case: $E \leq 0, \theta{ }_{1}^{\prime}\left(\hat{a}_{1}\right) \geq \theta{ }_{2}^{\prime}\left(\hat{a}_{2}\right), s_{1} \geq s_{2}$

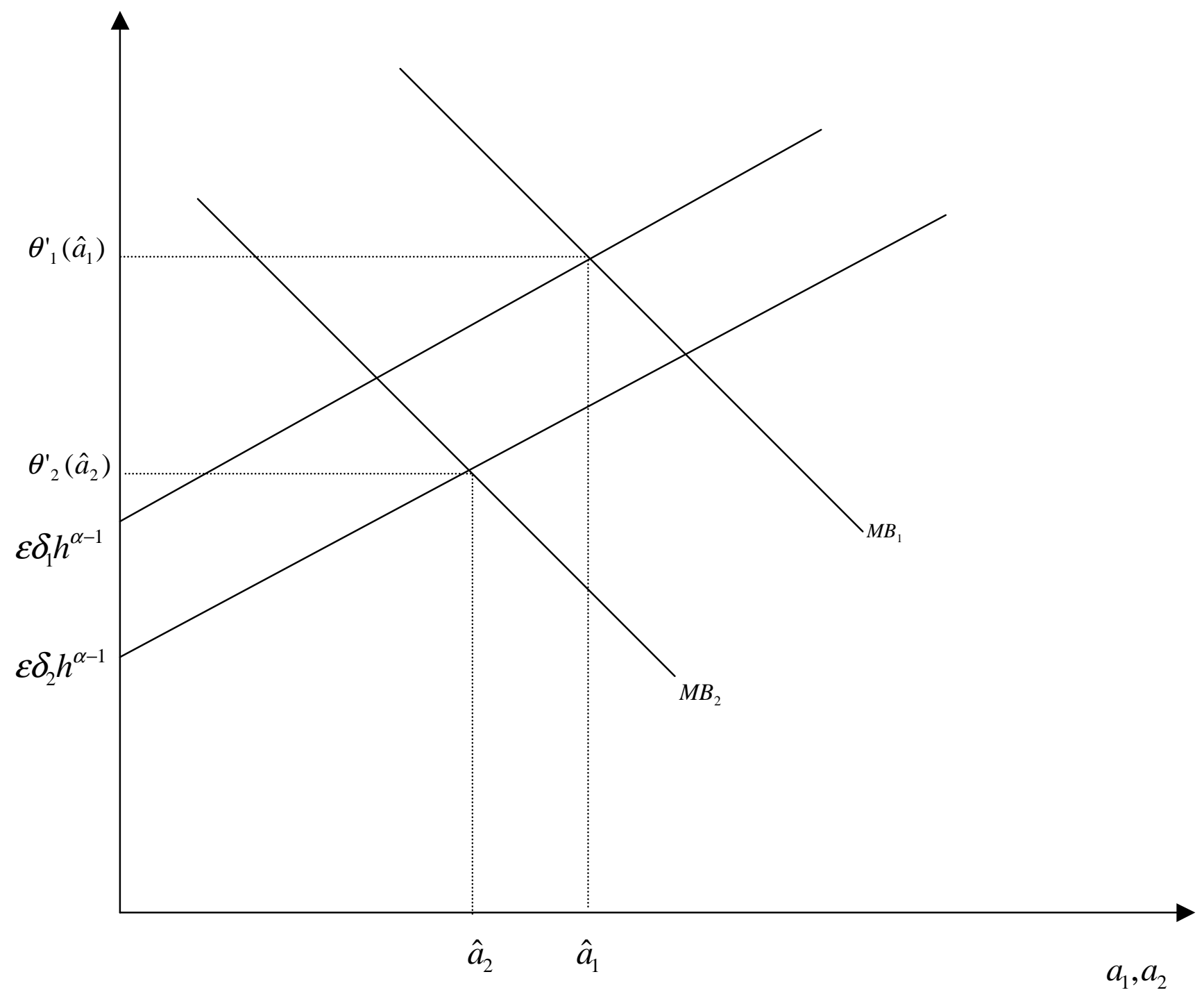


Figure 5

Asymmetric Cost Reductions

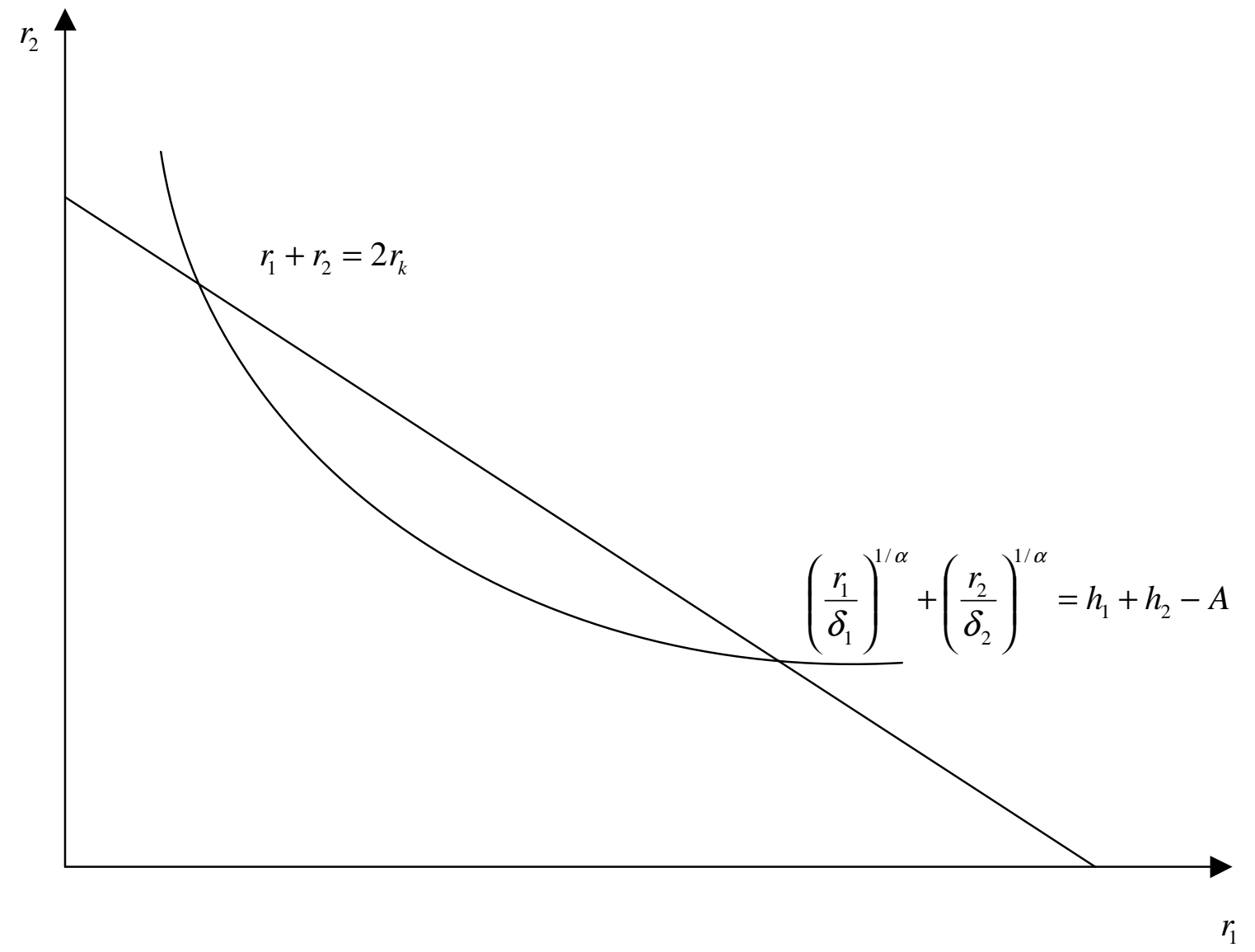




\section{Liste des publications au CIRANO *}

\section{Cahiers CIRANO / CIRANO Papers (ISSN 1198-8169)}

99c-1 Les Expos, l'OSM, les universités, les hôpitaux : Le coût d'un déficit de 400000 emplois au Québec — Expos, Montréal Symphony Orchestra, Universities, Hospitals: The Cost of a 400,000-Job Shortfall in Québec / Marcel Boyer

96c-1 Peut-on créer des emplois en réglementant le temps de travail? / Robert Lacroix

95c-2 Anomalies de marché et sélection des titres au Canada / Richard Guay, Jean-François L'Her et Jean-Marc Suret

95c-1 La réglementation incitative / Marcel Boyer

94c-3 L'importance relative des gouvernements: causes, conséquences et organisations alternative / Claude Montmarquette

94c-2 Commercial Bankruptcy and Financial Reorganization in Canada / Jocelyn Martel

94c-1 Faire ou faire faire : La perspective de l'économie des organisations / Michel Patry

\section{Série Scientifique / Scientific Series (ISSN 1198-8177)}

2000s-11 The Asian Financial Crisis: The Role of Derivative Securities Trading and Foreign Investors / Eric Ghysels et Junghoon Seon

2000s-10 Productivity Trends and Employment across Industries in Canada / Pierre Mohnen et Thijs ten Raa

2000s-09 Nouvelle économie, nouvelle organisation et technologies de l'information / Suzanne Rivard

2000s-08 Semi-Stationary Equilibrium in Leader-Follower Games / Ngo Van Long et Koji Shimomura

2000s-07 Strategic Behavior under Intertemporal Production Externalities / Richard Cornes, Ngo Van Long et Koji Shimomura

2000s-06 Preemption and Rent Dissipation with Multiple Investments / Marcel Boyer, Pierre Lasserre, Thomas Mariotti et Michel Moreaux

2000s-05 A Monte-Carlo Method for Optimal Portfolios / Jérôme Detemple, René Garcia et Marcel Rindisbacher

2000s-04 Cooperation in Public Goods Experiments / Claudia Keser (with comment by Claude Montmarquette)

2000s-03 The Illusion of Trust and Performance / Benoit A. Aubert et Barbara L. Kelsey

2000s-02 Risques à grande échelle dans les systèmes en réseau : quelques interrogations / Erwann Michel-Kerjan

2000s-01 Wealth Distribution, Moral Hazard, and Entrepreneurship / Sanjay Banerji et Ngo Van Long

* Vous pouvez consulter la liste complète des publications du CIRANO et les publications elles-mêmes sur notre site Internet à l'adresse suivante :

http://www.cirano.umontreal.ca/publication/documents.html 